\title{
Correction to: Considering different recent advancements in GNSS on real-time zenith troposphere estimates
}

\author{
Tomasz Hadas ${ }^{1,2} \odot \cdot$ Thomas Hobiger ${ }^{1} \cdot$ Pawel Hordyniec ${ }^{2,3}$
}

Published online: 10 September 2020

c) Springer-Verlag GmbH Germany, part of Springer Nature 2020

\section{Correction to: GPS Solutions (2020) 24:99 \\ https://doi.org/10.1007/s10291-020-01014-w}

In the original version of this article, equation (9) was displayed incorrectly. The correct equation is provided below:

$\left(G_{N} \cdot \cos a+G_{E} \cdot \sin a\right) \cdot \mathrm{mf}^{G}$

Publisher's Note Springer Nature remains neutral with regard to jurisdictional claims in published maps and institutional affiliations.

The original article can be found online at https://doi.org/10.1007/ s10291-020-01014-w.

Tomasz Hadas

tomasz.hadas@upwr.edu.pl

1 Institute of Navigation, University of Stuttgart, Breitscheidstrasse 2, 70174 Stuttgart, Germany

2 Institute of Geodesy and Geoinformatics, Wroclaw University of Environmental and Life Sciences, Grunwaldzka 53, 50-357 Wrocław, Poland

3 SPACE Research Centre, RMIT University, 402 Swanston Street, Melbourne, VIC 3001, Australia 